\title{
REPENSANDO AS RELAÇÕES CAMPO/CIDADE: uma abordagem acerca do terroir do vinho na Campanha Gaúcha
}

\section{RIVEDENDO LE RELAZIONI CAMPO/ CITTÀ: un approccio sullo terroir del vino in Campanha Gaúcha}

\author{
Vanessa Manfio \\ Doutoranda em Geografia \\ Universidade Federal do Rio Grande do Sul \\ nessamanfio@gmail.com.
}

Rosa Maria Vieira Medeiros

Pós-Doutorado em Geografia

Professora do Departamento de Geociências Universidade Federal do Rio Grande do Sul rmvmedeiros@ufrgs.br

\section{Luiz Fernando Mazzini Fontoura \\ Doutorado em Geografia \\ Professor do Departamento de Geociências \\ Universidade Federal do Rio Grande do Sul luiz.fontoura@terra.com.br}

\section{Resumo}

Ao longo dos tempos, as dinâmicas do campo vão sendo alteradas em função da técnica e do capital, implicando em modificações na relação rural-urbano, sendo o avanço do capitalismo o grande responsável pela artificialização do campo e o desenvolvimento da racionalidade deste espaço, além de atrair atividades não-agrícolas para o meio rural. Estas dinâmicas são observadas na criação de um terroir do vinho na Campanha Gaúcha que tem desencadeado novas organizações no meio de produção agrícola e no desenvolvimento rural. O presente texto busca entender as relações campo-cidade na Campanha Gaúcha a partir da inserção da vitivinicultura. Para alcançar o objetivo da pesquisa utiliza-se o método dialético e a abordagem qualitativa, privilegiando a interpretação dos dados e técnicas como entrevistas semi-estruturas, conversas informais, análise da paisagem e de leituras teóricas.

Palavras-Chave: Relação campo-cidade. Terroir do vinho. Campanha Gaúcha. Modernização agrícola. Geografia.

\section{Astratto}

Nel corso del tempo, le dinamiche del campo sono modificate a funzione della tecnica e del capitale, con conseguente a modifiche nel relazione rurale-urbano considerato il avanzo del capitalismo il grande responsabile del stato artificiale del campo e lo sviluppo della razionalità di questo spazio, oltre alle attrarre attività non agricoli per 
zone rurali. Queste dinamiche sono osservate nella creazione di un terroir del vino in Campanha Gaúcha che ha innescato nuove organizzazioni nel mezzo di produzione agricola e nel sviluppo rurale. Questo articolo cerca di comprendere le relazioni ruraliurbane in Campanha Gaúcha dall'inserimento del settore vino. Per raggiungere l'obiettivo della ricerca si usa il metodo dialettico e approccio qualitativo, privilegiando l'interpretazione dei dati e delle tecniche come la semi-strutture interviste, conversazioni informali, analisi del paesaggio e letture teoriche.

Parole-chiave: Relazione campo-città. Terroir del vino. Campanha Gaúcha. Modernizzazione agrícola. Geografia.

\section{Introdução}

As relações campo-cidade são foco de muitos estudos inclusive da geografia. Estas relações estão em constante transformação, principalmente com o desenvolvimento da modernização agrícola que passa a alterar os papéis dos espaços urbanos e rurais.

A modernização da agricultura traz uma modificação nas atividades, serviços e nas formas de trabalho, já que a mecanização e a monocultura diminuem o número de funcionários e alteram o sistema rural. Assim, o campo passa a ser, cada vez mais, artificializado e a natureza passa a ser menos decisiva na produção.

Aquele campo, caracterizado pela produção de excedentes agrícolas para as cidades adquiriu novas atividades e dinâmicas, deixando de ser espaço somente do agrícola. No campo, atualmente, vê-se a proliferação do turismo, da criação de cooperativas e indústrias associadas ao meio rural, de terroir e certificações geográficas.

Além disso, o capitalismo, em geral, promove o consumismo e a proliferação de mercadorias específicas para a população, atendendo gostos e culturas que também estão presentes em slogans de marketing. O campo passa a produzir alimentos característicos da procura do público citadino, como por exemplo: os produtos orgânicos que servem uma determinada população, geralmente pessoas de melhor poder aquisitivo.

$\mathrm{Na}$ Campanha Gaúcha, o espaço rural altera-se em função do desenvolvimento da vitivinicultura, propiciando o surgimento do turismo, da industrialização da uva, da comercialização do vinho, entre outras atividades. 
Dessa maneira, o objetivo principal desta discussão é entender as relações campo-cidade a partir da modernização da agricultura, do turismo rural e da formação de um terroir do vinho na Campanha Gaúcha.

Para cumprir os objetivos do presente estudo utilizaram-se as ideias e análises dos seguintes autores e trabalhos: Lefebvre (1969, 1999), Santos (1996), Fontoura (2004, 2009), Hespanhol (2013), Flores (2011), Falcade (2005), entre outros. Ademais, a pesquisa contou com a abordagem qualitativa e o método dialético, tendo como técnicas metodológicas: trabalho de campo com a aplicação de entrevista semiestruturada, análise da paisagem e conversas informais, além do diário de campo e revisão de literatura.

A apresentação deste texto está articulada em duas partes: a primeira de reflexão sobre a modernização agrícola e as relações campo-cidade e a segunda de análise do território do vinho da Campanha Gaúcha e as novas relações entre os espaços urbanos e rurais.

\section{A modernização agrícola e a relação campo-cidade: discussões teórico-conceituais}

A discussão da relação campo-cidade não é recente, mas vem sendo intensamente estudada, nos últimos anos, com o interesse de diversos pesquisadores e ciências, tendo em vista, a crescente dinâmica destes espaços e a interação entre eles. Segundo os autores Silva e Hespanhol (2011) o debate sobre o urbano/rural, cidade/campo não é uma preocupação científica recente, pois estudos da Sociologia estadunidense demonstravam interesse em delimitar e compreender os aspectos circunscritos a tal temática, ainda no início do século XX.

Pode-se dizer que essa relação existe desde o surgimento da cidade, no entanto, torna-se mais evidente quando o campo passa a produzir mais alimentos do que necessita e gera excedentes capazes de garantir a subsistência da cidade (FONTOURA, 2009).

As relações de trocas de serviços entre os dois espaços: cidade e campo revelam as distinções espaciais existentes entre eles, principalmente pelas suas condições de vida e trabalho. Conforme Fontoura (2011, p 44) "uma diferença importante entre o campo e 
a cidade, bem como o que influencia diretamente sobre a produção da riqueza, é o papel da terra ou o seu uso do solo e a sua apropriação."

Para o campo, a terra representa o sustento, a produção de alimentos e a moradia. Enquanto, na cidade a terra cumpre um papel diferenciado, representando a localização e assentamento urbano, sendo as atividades produzidas pelo homem e pelas tecnologias (HARVEY, 1980).

Dessa forma, ao conceitualizar o campo Medeiros (2011, p. 59-60) diz que ele "pode ser compreendido como recurso a partir do seu modo produtivo (agricultura, pecuária, agroindústria, turismo, etc...) e como um modo de vida enquanto local de residência e de lazer."

Nesse sentido, o campo abriga atividades da produção de alimentos, do contato direto com a terra, já a cidade tem como tarefas: a industrialização, circulação e prestação de serviços. Esta diferenciação permite entender as dinâmicas e a relação estabelecida entre estes espaços, cujos produtos do campo são transformados e comercializados no espaço citadino.

A cidade é o lugar do encontro das coisas, das pessoas, da troca, adquirindo independência sobre o campo (LEFEBVRE, 1999), efeitos da presença dos espaços de gestão governamental, administração de serviços e da concentração populacional.

A concentração e dispersão de serviços e população também são marcas da diferenciação destes dois espaços. Para Abramovay (2000) as cidades ficam reconhecidas pela concentração demográfica enquanto o campo pela dispersão. Já no patamar das atividades, o campo está centrado nas atividades primárias e as cidades no setor secundário e terciário.

Ainda, a separação entre cidade e campo toma lugar, a partir da diferenciação social do trabalho material e intelectual, onde a cidade cabe às funções de organização, direção de atividades políticas e a elaboração de conhecimentos, e o campo a produção de elementos básicos para sobrevivência da sociedade (LEFEBVRE, 1969).

Entretanto, estas diferenciações utilizadas entre campo e cidade vêm sendo alteradas, nas últimas décadas, devido à modernização do campo. Com o avanço de tecnologia no meio rural tem-se visto novas dinâmicas, outras relações espaciais e a presença da racionalidade no campo. 
A racionalidade do campo é entendida por Santos (1996) como a extensão dos domínios da sociedade submetidos aos critérios da decisão racional, ou a forma capitalista da atividade econômica que invade o espaço rural. Ainda, em Santos (1996) a racionalidade seria entendida como o progresso de administração das coisas, das quais, subentende-se que elas teriam o condão de direção do comportamento dos homens.

É possível compreender a racionalidade como domínios de conhecimento e decisão sobre diferentes lógicas, objetivando resolver problemas e difundir as atividades espaciais. Dessa forma, Santos (1996) coloca que com o advento da globalização, a especialização agrícola - baseada na ciência e na técnica - inclui o campo modernizado em uma lógica competitiva que acelera a entrada da racionalidade em todos os aspectos da atividade produtiva, desde a reorganização do território aos modelos de intercâmbio até mesmo as relações interpessoais.

Diante da reorganização do território, o rural passa a ser analisado a partir de um ponto de vista próprio, pois ao abordarmos este espaço sob a perspectiva urbana pode-se obter uma visão distorcida (MEDEIROS, 2006). As novas mudanças no cenário campocidade resultam da presença de novas características e modos de vida, necessitando novos olhares sobre estes espaços para entender a conjuntura que os totaliza.

O campo não é mais espaço bucólico e de apenas "leves" relações homem/natureza que ocasionam poucas alterações espaciais. A modernização invade o campo e altera o espaço natural, artificializando as formas preexistentes e a condução dos processos, pois a técnica e a ciência aceleram a produção agrícola e reestruturam o ciclo ambiental do campo, como exemplo a inserção dos transgênicos que modificam a cadeia alimentar biológica e o ecossistema.

A modernização do campo tem sua consolidação, no Brasil, nas décadas de 1960 e 1970, com a vinda de multinacionais para o país, juntamente com os incentivos governamentais e a implantação do pacote tecnológico como coloca Hespanhol (2007, p. 190):

Muitas indústrias vinculadas à agropecuária se implantaram no país ao longo dos anos 60 e 70, em razão dos estímulos oferecidos pelo Estado e do promissor mercado brasileiro, que foi artificialmente ampliado pelas políticas modernizantes, notadamente pela oferta de 
crédito rural em grande volume e por baixas taxas de juros para a aquisição de máquinas, implementos e insumos químicos.

Essas transformações ocorridas no Brasil depois das políticas implantadas por Getúlio Vargas e Juscelino Kubitschek, envolvendo o âmbito político e econômico, repercutiram na passagem de um país agrário-exportador para um país industrial-urbano (SILVA, 2006).

Para Calaça (2009) a modernização agrícola é entendida como um conjunto de transformações que envolvem a agregação do capital na base técnica da produção, tendo como resultado a alteração das relações de trabalho, uso de terra, produção agrícola, a necessidade de procura de novas áreas de trabalho dos produtores rurais e a destruição das culturais tradicionais.

A modernização mencionada propiciou uma reorganização da força produtiva e formas de trabalho no campo, dos quais muitos trabalhadores rurais foram expulsos pela introdução da máquina, ou mesmo pela falta de qualificação para atuar com os novos equipamentos ou elementos tecnológicos. Para Rambo e Fontoura (2007, p. 5) “pode-se considerar que a modernização da agricultura, apesar de ter proporcionado um incremento técnico e tecnológico, também tem levado a exclusão das pequenas propriedades".

A inserção destas tecnologias deixou o proprietário rural subordinado ao capitalismo, ou seja, dependente de financiamentos governamentais e da produção citadina (como maquinários, sementes e insumos agrícolas). Segundo Fontoura (2004) os produtores rurais passam a inserir a rotação do capital na agricultura, artificializando o tempo de produção e de trabalho através do crédito subsidiado.

Além disso, os agricultores investem na produção de alimentos e bens especializados para atender um nicho de mercado. Nas palavras de Fontoura (2009, p. 282) “o campo passa a produzir um produto específico para um segmento específico de consumidor urbano que se relaciona com o seu imaginário, valores e até mesmo fetiche". Dessa forma, cria-se uma nova relação campo-cidade que garante a reprodução capitalista contemporânea, flexível e globalizada (FONTOURA, 2009).

Ainda, novas atividades estão sendo inseridas no meio rural conforme Rambo e Fontoura (2007, p. 8), surgem no campo: 
[...] atividades rurais não-agrícolas, relativamente inovadoras, como atividades turísticas, o chamado turismo rural (rotas turísticas, balneários, trilhas, pesquepague, etc), produções orgânicas e/ou agroecológicas, agroindústrias (alimentares, de artesanato, etc), certificação de qualidade de produtos, marketing sobre a produção familiar, o que vem atribuir novos valores ao campo, não restringindoo a um simples fornecedor de alimentos e matérias-primas para a cidade.

Neste campo modernizado desenvolve-se também a proliferação de associações e de redes integrando campo e cidade como argumenta Müller (1989): a modernização do campo permite a integração entre indústria e agricultura, fazendo com que as empresas ou os grupos econômicos influenciem as atividades agrárias para beneficiar seus interesses capitalistas.

A integração entre indústria e agricultura permite que a produção agrícola seja transformada nos arredores do campo ou no próprio espaço da produção para minimização dos custos de transporte (como exemplo: as unidades da Indústria SADIA que se instalam próximas de propriedades de produção de suínos e aves) ou que empresas tenham uma forte influência sobre a produção agropecuária. Sobre isso Oliveira e Miorin (2011, p.7) mencionam,

No caso da produção suína, muito comum nos estados do Sul do Brasil, as grandes empresas unem-se a pequenos produtores rurais, sendo que estes fornecem a mão-de-obra, criando o que será matériaprima para indústria, segundo as especificidades estabelecidas e nos prazos acordados. Enquanto são as indústrias que se responsabilizam pelo fornecimento de filhotes e rações, elas determinam as regras de processamento do produto final bem como da comercialização.

Com isto, o rural pode ser entendido como um espaço incorporado/incorporador do processo de urbanização, já que participa de circuitos e redes e está inserido na lógica capitalista de mercado, utilizando-se de técnicas para o aumento e especificialização da produção (CANDITTO; CORRÊA, 2008).

A especificialização produtiva presente no campo moderno pode ser vista na atividade da vitivinicultura da Campanha Gaúcha, localizada na região fronteiriça do sudoeste do Rio Grande do Sul, Brasil, que tem buscado criar um terroir do vinho fino, produzido com uvas viníferas européias (como Cabernet Sauvignon, Chardonnay, Tannat e Merlot). 
Diante do exposto, nota-se uma mudança nas relações campo/cidade redefinindo os papéis rurais, aproximando os dois ambientes. Mota e Schmitz (2002) afirmam que há uma progressiva ampliação do fluxo de pessoas, matérias-primas, informações no campo e a tendência de diversificação das atividades econômicas que alteram as antigas diferenças entre campo-cidade.

$\mathrm{Na}$ visão de Hespanhol (2013) atualmente não se pode identificar o campo apenas como o local de realização da atividade agropecuária, pois outras atividades (como o processamento artesanal), funções (de moradia, lazer e turismo, ambiental etc.) e sujeitos (como os assentados neorurais) têm sido incorporados ao meio rural. Com isso, "ampliam-se as coexistências, as contradições e os conflitos entre diferentes temporalidades e espacialidades presentes no rural" (HESPANHOL, 2013, p. 109).

Os espaços: urbano e rural são representados, cada vez mais, pela ciência e pela técnica, tendo como mediador dessas relações à divisão internacional do trabalho e a efetividade técnica. Por essa perspectiva, o campo e a cidade ganham novos arranjos técnicos, teias que integram local/global e natural/artificial (SANTOS, 1996).

Ademais, atividades e modos de vidas do campo invadem as cidades e viceversa como afirma Hespanhol (2013, p. 109),

O espaço e a sociedade rural mudaram, pois parte da população residente no campo incorporou hábitos urbanos em decorrência da expansão da infraestrutura, da maior fluidez propiciada pela melhoria das vias e dos meios de transporte e do intenso fluxo de informações veiculadas pelas mídias, principalmente pela televisão. Assim, como parte da população rural que migrou para as cidades também procura manter o seu modo de vida, por meio do cultivo de hortas e da criação de pequenos animais nos quintais, bem como pelas manifestações culturais e religiosas.

O rural contemporâneo é um espaço ressignificado, exigindo a construção de novas identidades e territorialidades a partir da valorização de outras dimensões do território, não somente a econômica (FLORIANI, 2007).

Nesta perspectiva, as relações campo-cidade, na contemporaneidade, mostram uma proximidade destes espaços e a inserção de novas atividades, principalmente no campo, deixando um desafio à ciência geográfica e demais áreas de conhecimento em estudar as novas relações campo/cidade e as contradições espaciais e sociais. 
As relações campo-cidade na Campanha Gaúcha - RS a partir do desenvolvimento da vitivinicultura

A vitivinicultura é uma atividade significativa no Rio Grande do Sul, especialmente na Serra Gaúcha, atrelada às condições ambientais e culturais da região. Esta atividade atingiu o mercado interno/externo e desenvolveu uma identidade e territorialização do vinho na região (PROTAS; CAMARGO; MELO, 2014).

Porém, com o aumento da competitividade com as áreas vinícolas de outros países vizinhos, a falta de espaço para expansão da produção de vinho na Serra Gaúcha e a descoberta de novas áreas com condições edafoclimáticas ${ }^{1}$ adequadas para 0 desenvolvimento da vitivinicultura ocorre à expansão desta atividade para Campanha Gaúcha. Segundo Falcade (2011) vários fatores contribuíram para expansão da vitivinicultura no Rio Grande do Sul inclusive para Campanha, conferindo a esta região a produção de vinhos finos.

Além disso, a Campanha Gaúcha, palco de problemas sociais e do sistema de produção agropecuária diferenciado do restando do Rio Grande do Sul tem investido na vitivinicultura, a fim de promover o desenvolvimento socioeconômico regional.

Essa vitivinicultura que se desenvolve na Campanha Gaúcha caracteriza-se pelo poder de agregação de valor na produção, seja pelo incremento de novos produtos, seja pela variedade da produção de vinhos a partir de diferentes castas de uvas e pela crescente tecnologia envolvida na produção de vinhos finos (COPELLO, 2015).

A agregação de valores também é vista pela formação de um novo marketing para o consumo de vinhos como o da Vinícola Dunamis de Dom Pedrito envolto na filosofia de vinhos leves e descomplicados que podem ser saboreados em qualquer lugar e momento ou da incorporação de uma identidade da cultura gaúcha com os vinhos como é visto nos discursos e produtos da Vinícola Guatambu - Estância do Vinho também de Dom Pedrito.

Convém destacar, que ao abordar a questão da uva e do vinho na Campanha Gaúcha estabeleceu-se um recorte espacial, dos quais abrange os seguintes municípios:

\footnotetext{
${ }^{1}$ Descoberta de novas áreas vitícolas no Rio Grande do Sul, inclusive das potencialidades da Metade Sul, através de estudos como o Zoneamento Agroclimático da década de 1960 e de estudos científicos liderados pelo governo e universidades.
} 
Alegrete, Bagé, Candiota, Dom Pedrito, Itaqui, Hulha Negra, Quaraí, Rosário do Sul, Santana do Livramento e Uruguaiana (Mapa 1).

Mapa 1: Localização dos municípios produtores de vinhos finos da Campanha Gaúcha

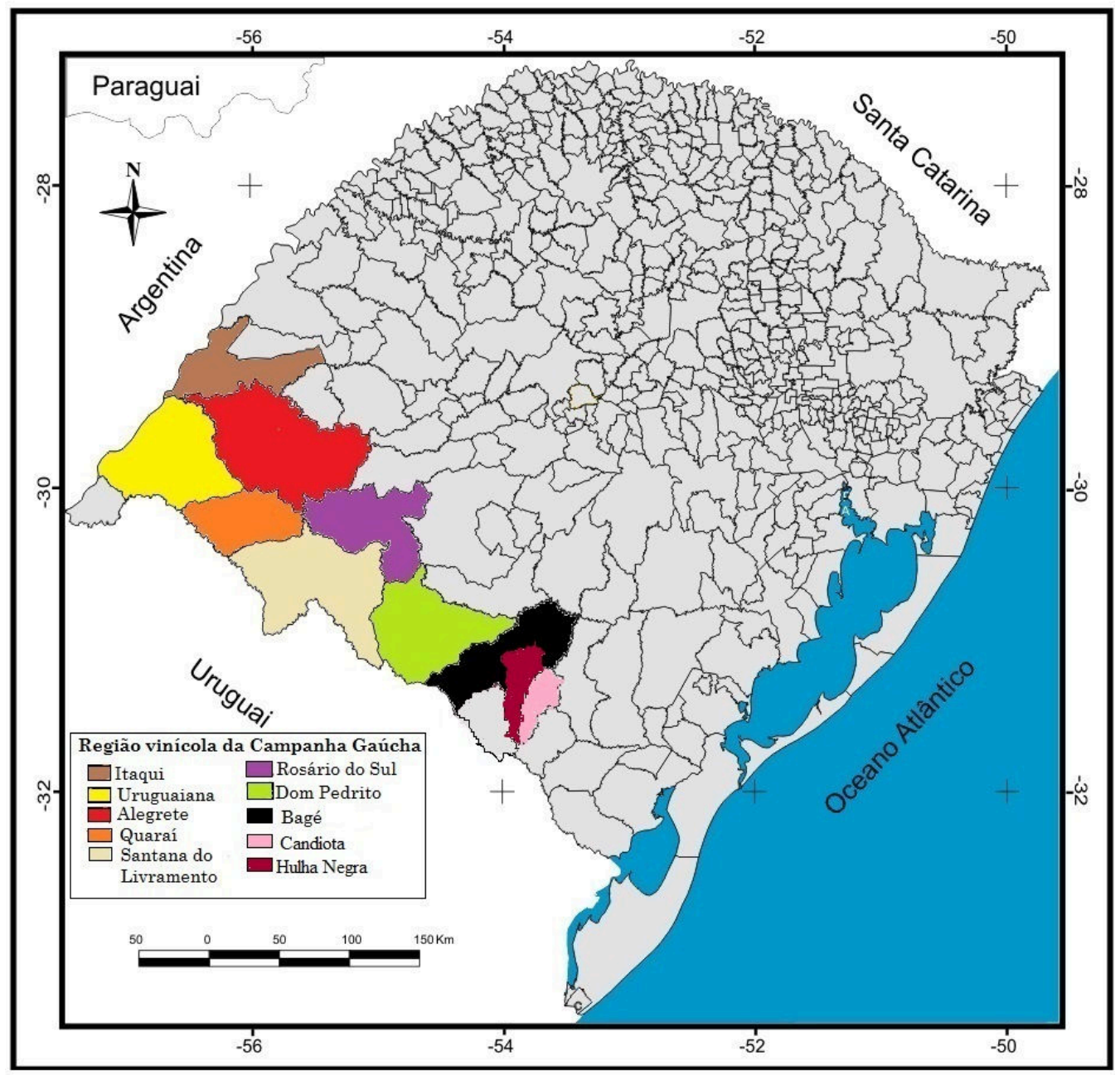

Fonte: IBGE (2015), adaptado por Vanessa Manfio

Retomando a questão de identidade e valores aos vinhos, a produção de vinho na Campanha Gaúcha repercutiu na busca por uma identificação vitícola, associado à vitivinicultura a cultura gaúcha, a história e ao ambiente regional. Em Flores (2015, p. 60-61) é destacado que

O apelo histórico se dá colocando em evidência o gaúcho e fatos locais, como a Revolução Farroupilha. O vinho não aparece como parte histórica da identidade, mas como elemento atual que carrega e sintetiza marcos da identidade local do gaúcho e da Campanha. 
Dessa maneira, a Campanha Gaúcha tem buscando criar um novo terroir do vinho. Esta criação de um terroir está relacionada aos efeitos da ascensão da globalização e das especificidades no consumo, pois cada vez mais, o mercado capitalista tenta produzir novos elementos e materiais que despertem o consumismo da população. Assim, as pessoas são incentivadas a comprar produtos que conheceram através do marketing e pela sua qualidade diferenciada.

Diante disso, o surgimento de terroir diferencia o produto, associando-o ao ambiente e sociedade da produção. Para Flores e Fontoura (2010) o terroir é um termo muito utilizado para os vinhos e designa uma área pequena de solo e microclima específicos que vão determinar qualidades especiais ao produto. A constituição de um terroir implica fatores simbólicos e subjetivos na relação com o espaço, envolvendo ação social, relações culturais, discurso de sustentabilidade, solidariedade e exploração dos produtos.

Observa-se que a incessante busca por renda impõe a procura de critérios de especialidade, singularidade, originalidade e autenticidade, em cada um desses domínios. Se não puder estabelecer a singularidade pelo apelo ao terroir e à tradição, ou pela descrição direta do sabor, outros modos de distinção deverão ser invocados para o mercado do consumo (HARVEY, 2005).

Referindo-se ao terroir vitícola, Pitte (2012) coloca que este é marcado pelo tipo de solo próprio, microclima, disponibilidade de água, relevo, técnicas e conhecimento específico que marcam as potencialidades do espaço para produção de vinhos.

O terroir vitícola permite o desenvolvimento de outras atividades como é observado na vitivinicultura da Campanha Gaúcha que compõe um novo território do vinho e que incorporado a este tem proporcionado novas iniciativas produtivas: o turismo e os eventos gastronômicos regionais como o $1^{\circ}$ Festival Binacional de EnoGastronomia e Produtos do Pampa (Dados do trabalho de campo).

Ainda, o terroir do vinho da Campanha, que está sendo constituído, é marcado também pela produção de vinhos finos elaborados a partir de uvas viníferas européias e sistema de condução das videiras em espaldeira. Estas características marcam uma vitivinicultura contemporânea que associado com a paisagem plana da região compõem uma paisagem única. Percebe-se que a vitivinicultura traz uma alteração na apropriação 
espacial que antes era marcada, principalmente pela pecuária e hoje é também marcado pelo vinho e turismo.

Com isto, novas atividades econômicas estão sendo, gradativamente, inseridas na Campanha Gaúcha, transformando a paisagem produtiva e as relações de trabalho local/regional (BRUM NETO; BEZZI, 2009).

Neste sentido, Flores e Medeiros (2013, p. 17) colocam que:

[...] as novas ruralidades acabam por sintetizar novas formas de apropriação do espaço, novas territorialidades, agregando funcionalidades ao rural, o que aumenta sua complexidade. $\mathrm{O}$ ingresso da Campanha no mundo dos vinhos traz para seus atores novas oportunidades e desafios, na medida em que colocam o território em outros circuitos.

A vitivinicultura é uma atividade elitizada que produz uma valorização do campo e da sociedade da Campanha Gaúcha, trazendo novas relações campo-cidade, principalmente na industrialização do vinho, com modernas vinícolas espalhadas nas áreas de parreirais e equipamentos tecnológicos (tratores, pulverizadores de insumos, entre outros) e pelo enoturismo que ora se inicia na região.

Nesta linha de raciocínio, a vitivinicultura tem promovido um desenvolvimento social e econômico na Campanha Gaúcha através de novos atores locais, atividades e políticas públicas, alavancando sua produção e suas perspectivas regionais. Entre os atores do território do vinho fino na Campanha Gaúcha está a Associação de Produtores de Vinhos Finos ${ }^{2}$ (APVF) como pode ser visualizado no Esquema 1.

\footnotetext{
${ }^{2}$ A Associação dos Produtores de Vinhos Finos da Campanha Gaúcha foi criada em 2010 e também é conhecida como Associação Vinhos da Campanha.
} 
Esquema 1: Esquema com os membros da Associação de Vinhos Finos da Campanha

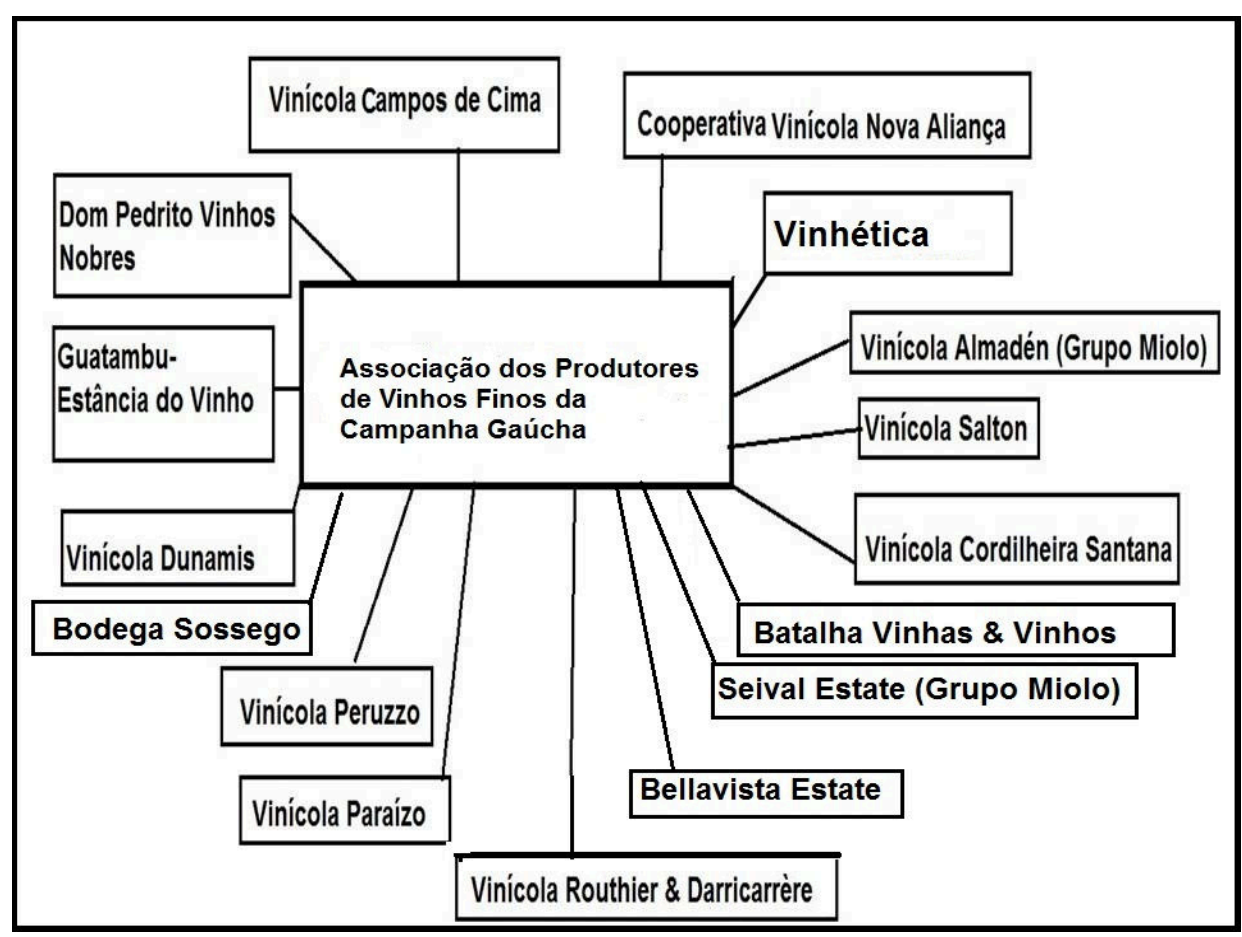

Fonte: Associação de Vinhos Finos da Campanha Gaúcha (26 de abril de 2016) Org.: MANFIO, $\mathrm{V}$.

$\mathrm{Na}$ associação mencionada anteriormente fazem parte dois tipos de empresas: as empresas vinícolas provenientes da Serra Gaúcha como Salton, Almadén (Grupo Miolo), Cooperativa Nova Aliança e as empresas vinícolas locais com uma estrutura menor e especializada para um público de melhor poder aquisitivo como Cordilheira Santana, Vinícola Routhier \& Darricarrère, Dunamis, Guatambu e Dom Pedrito Vinhos Nobres, entre outras (Esquema 1).

A APVF e as empresas membros da associação têm permitido a racionalidade do espaço rural da Campanha Gaúcha através do marketing, das formas vinícolas, do desenvolvimento do enoturismo e do comércio vinícola, como destaca Engelmann (2009) a atividade vinícola trouxe consigo uma nova racionalidade, baseada no mercado e na competitividade, tendo as empresas como agentes desta condição.

No que diz respeito, ao turismo ao espaço vinícola este tem sido realizado pelas vinícolas e associações na categoria de passeios turísticos, cavalgadas entre os parreirais, almoços com degustação de vinho e culinária local, congressos sobre vitivinicultura e eventos de vindima, onde o turista pode participar da colheita da uva. 
Evidentemente, a articulação da Associação de Produtores de Vinhos Finos da Campanha Gaúcha em 2010, contribuiu para a construção do território do vinho e divulgação do turismo e vitivinicultura da Campanha. Atualmente, essa associação, juntamente com apoio da Empresa Brasileira de Pesquisa Agropecuária (EMPRAPA Uva e Vinho) tem buscado a Indicação Geográfica para os vinhos da Campanha Gaúcha sobre a forma de Indicação de Procedência.

Esse registro de Indicação Geográfica (IG) é conferido a produtos que são característicos de um local com qualidades únicas de recursos naturais e culturais, criando uma identidade própria, distinguindo-os dos seus similares disponíveis no mercado. Para Falcade (2005) as IGs podem ser de dois tipos: as Indicações de Procedência (IP) e a Denominação de Origem (DO), sendo a primeira referente ao nome geográfico do local ou território que é conhecido como ponto de extração, produção ou fabricação de um produto ou serviço; e a segunda é o nome geográfico do lugar ou território que designa produto ou serviço, dos quais as qualidades ou características dos produtos relacionam-se ao meio geográfico e aos aspectos humanos (FALCADE, 2005).

Na perspectiva de Barham (2003), os Indicadores Geográficos (IGs) são um registro que define um produto originário de um território que lhe confere qualidade, reputação além de outras características relativas ao lugar geográfico de origem.

Discorre ainda Flores (2011, p.120) que: "os vinhos da região tendem a fazer referência a expressões da Campanha, promovendo uma ligação desses valores e paisagens com o vinho - como a figura dos cerros no rótulo, como referência ao pampa." Nota-se no próprio nome dos vinhos os elementos de identificação com a região, seja a cultura gaúcha, a pecuária ou ao ambiente natural (Ilustração 1). 
Ilustração 1: Vinhos da Guatambu - Estância do Vinho

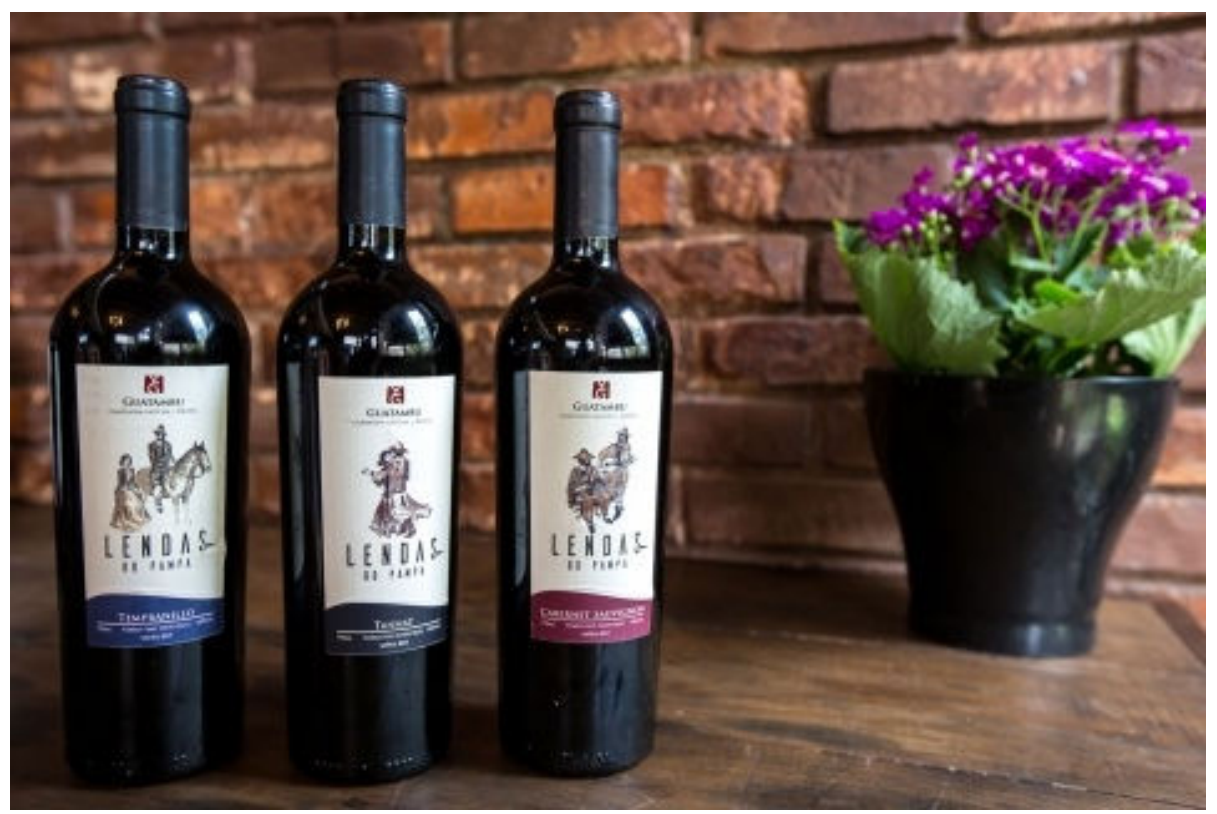

Fonte: foto tirada por André Feltes, disponível em:

http://www.guatambuvinhos.com.br/album.php?ida=6\#divMenuUtil

Nesse sentido, o processo de reconhecimento da Indicação Geográfica da Campanha encontra-se em desenvolvimento, viabilizando a produção associada a uma identidade do produto. Para Peres (2016, grifo nosso) a implantação da Indicação Geográfica da Campanha Gaúcha permitirá a consolidação do território do vinho e a participação dos produtos vinícolas desta região no mercado mundial, com preços mais elevados e com a garantia de qualidade para concorrer com os outros produtos nacionais e internacionais.

Além disso, com a Indicação Geográfica, os produtos vinícolas na Campanha terão maior visibilidade nacional e internacional, o que contribui para o interesse de pessoas em conhecer a região, fortalecendo o turismo (FOTUNATO, 2016, grifo nosso).

Ademais, APVF busca desenvolver melhores condições de comércio, de produção de uva e vinho, obtendo parcerias com instituições de ensino e pesquisa como: a EMBRAPA, Universidade Federal de Santa Maria, Universidade Federal do Pampa, e a Universidade Federal do Rio Grande do Sul, entre outras. Além de atrair capital nacional e estrangeiro, tecnologia e políticas públicas. Como afirma Flores (2011) coloca que a vitivinicultura na Campanha Gaúcha está alinhada a programas governamentais que incentivam a dinamização e desenvolvimento regional. 
De modo geral, as perspectivas de consolidação da vitivinicultura e do turismo rural dependerão do amadurecimento dos atores e o fortalecimento das suas relações dentro do quadro cooperativo e produtivo (FLORES, 2011).

A vitivinicultura na Campanha Gaúcha também tem proporcionado a criação de cursos de enologia e pesquisas voltadas ao setor dos vinhos, para atender a nova demanda de profissionais requeridos pelo mercado vinícola regional.

Outro aspecto importante é que as cidades da Campanha Gaúcha estão revitalizando-se, através do melhoramento de infraestruturas como hotéis, restaurantes, acessibilidade e espaços públicos e reconstrução de espaços públicos históricos da região, para atender os turistas que vêm motivados a descobrir o mundo dos vinhos. Como exemplo, o projeto de revitalização da estrada e estação férrea de Santa do Livramento e a revitalização do Forte Santa $\mathrm{Tecla}^{3}$ de Bagé.

Em resumo, o fortalecimento da vitivinicultura na Campanha Gaúcha é significativo para o desenvolvimento regional, pois cria novas potencialidades e transforma as relações campo-cidade da região, através do turismo vitícola e da produção e comercialização de vinhos finos, trazendo uma racionalidade para o campo com a criação de cursos e eventos enoturísticos, infraestrutura e conhecimento técnico científico.

\section{Considerações finais}

O debate sobre as relações campo-cidade é importante para entender o modo de vida, as formas e trabalho que permeia a constituição dos espaços. Esta relação é antiga, dos quais o campo era visto como espaço natural, modesto e de produção de excedentes agrícolas fornecidos às cidades. Todavia, a cidade era vista como espaço de concentração populacional, da gestão administrativa e também do conhecimento intelectual.

\footnotetext{
${ }^{3}$ O Forte de Santa Tecla foi fundado em 1774, pelo Governador de Buenos Aires Dom Juan José Vertiz y Salcedo, no contexto da invasão espanhola na região que tinha como meta expulsar os portugueses do território gaúcho. Trata-se de um ponto histórico da região localizado próximo as áreas de vitivinicultura de Bagé (PERUZZO, 2016).
} 
Com o desenvolvimento do capitalismo, o campo e a cidade se reestruturam transformando a relação campo-cidade, principalmente devido à inserção de novas atividades no rural, dinâmicas econômicas e tecnologias.

Entre estas atividades e dinâmicas, presentes no campo, principalmente no espaço vinícola, estão o turismo, a certificação geográfica e a formação de terroir, ponto-chave do capitalismo rural. Esta realidade é vista na região da Campanha Gaúcha, cujas novas atividades do rural associadas à vitivinicultura têm proporcionado novas relações campo-cidade.

Na Campanha Gaúcha a formação de um terroir do vinho fino evidenciou a intensificação das técnicas ao campo, atraindo muitos investidores e a construção de ambientes dignos da modernidade, como vinícolas requintadas.

A articulação entre o terroir do vinho da Campanha e a cultura gaúcha é amplamente utilizada no marketing e na diferenciação dos produtos regionais, agregando valores e qualidade à uva e ao vinho o que permite uma racionalidade do campo. Ainda, a conquista de uma certificação geográfica orientada pela Associação de Produtores de Vinhos Finos da Campanha Gaúcha irá permitir o reconhecimento internacional dos vinhos da Campanha Gaúcha e o fortalecimento das atividades de enoturismo e do terroir.

Além disso, a formação do terroir do vinho na Campanha Gaúcha tem implicado na reestruturação das cidades, pelo fato de fornecer profissionais, tecnologia e criar melhores infraestruturas para atender os turistas que procuraram os atrativos enoturísticos.

Por fim, pensar na relação campo-cidade da Campanha Gaúcha, na atualidade, requer ter em mente as múltiplas dimensões: econômica, social, histórica, cultural, paisagística e as potencialidades vinícolas que tornam essa relação complexa e vital para o desenvolvimento regional.

\section{Referências}

ABRAMOVAY, R. Funções e medidas da ruralidade no desenvolvimento contemporâneo. IPEA, n. 702, 2000, 33p. Disponível em:

http://repositorio.ipea.gov.br/bitstream/11058/2360/1/TD_702.pdf. Acesso em: maio 2014. 
ASSOCIAÇÃO VINHOS DA CAMPANHA. Região da Campanha se transforma em Centro de Vinhos Finos. Nov. 2012. Disponível em:

http://www.vinhosdacampanha.com.br/. Acesso em: 12 jun. 2014.

BARHAM, E. Translating terroir: the global challenge of French AOC labeling. Journal of Rural Studies. Filadélfia, Pensilvânia, EUA. vol. 19, n. 1, p. 127-138, jan. 2003.

BRUM NETO, H.; BEZZI, M. L. Região, Identidade Cultural e Regionalismo. Temas \& Matizes. Dossiê: Relações Campo-Cidade. Cascavel - PR, n. 16, p.65-96, 2009.

CALAÇA, M. Agroindústria e modernização do campo no Cerrado. In: MEDEIROS, R. M. V.; FALCADE, I. (org.). Tradição versus tecnologia: s novas territorialidades do espaço agrário brasileiro. Porto Alegre: Ed. da UFRGS, 2009. p. 225- 268.

CANDIOTTO, L. Z. P.; CORREAA, W. K. Ruralidades, urbanidades e a tecnicização do rural no contexto do debate cidade-campo. CAMPO-TERRITÓRIO: revista de geografia agrária, v.3, n. 5, p. 214-242, fev. 2008. Disponível em:

http://www.seer.ufu.br/index.php/campoterritorio/article/viewFile/11839/6928. Acesso em: 3 jun. 2014.

COPELlO, M. As regiões produtoras do Brasil. Revista Anuário Vinho do Brasil. Baco multimídias. São Paulo. SP. 2015.

ENGELMANN, D. Da estância ao parreiral: um estudo de caso sobre a vitivinicultura em Santana do Livramento. Dissertação - Universidade Federal do Rio Grande do Sul, Escola de Administração, Programa de Pós Graduação em Administração. Porto Alegre: 2009.

FALCADE, I. Indicação Geográfica, o caso da região com indicação de procedência Vale dos Vinhedos. 2005. 109f. Dissertação (mestrado em Geografia)- Universidade Federal do Rio Grande do Sul, Porto Alegre, 2005.

. As Indicações Geográficas (IG's) e a reorganização do espaço rural brasileiro. In: MARAFRON, G. J.; RUA, J.; RIBEIRO, M. A. (org.). Abordagens teórico-metodológicas em Geografia Agrária. Rio de Janeiro: Ed da UERJ, 2007. p. 225-253.

.A paisagem como representação espacial: a paisagem vitícola como símbolo das indicações de Procedência de vinhos das regiões dos Vinhedos, Pinto Bandeira e Monte Belo (Brasil). 2011. 310f. Tese (Doutorado em Geografia) Universidade Federal do Rio Grande do Sul; Universidade de Borgonha, Porto Alegre; Dijon (França), 2011.

FLORIANI, N. O planejamento do espaço rural periurbano: da abordagem funcional do território às territorialidades da autonomia. Desenvolvimento e Meio Ambiente. Curitiba, n. 16, p. 55-68, jul./dez. 2007. 
FLORES, S. S.; FONTOURA, L. F. M. Do desenvolvimento ao desenvolvimento territorial sustentável: estratégias e alternativas de inclusão através dos terroirs do vinho e da agroecologia. In: ENCONTRO NACIONAL DE GEÓGRAFOS, XVI., 2010. Porto Alegre. Anais... Porto Alegre. jul. 2010. Disponível em: www.agb.org.br/evento/download.php?idTrabalho=3772. Acesso em: 4 jun. 2014 .

FLORES, S. S. Desenvolvimento territorial sustentável a partir dos territórios do vinho: O caso dos "Vinhos da Campanha." 2011. 153f. Dissertação (Mestrado em Geografia) - Universidade Federal do Rio Grande do Sul, Porto Alegre, 2011.

Vinho e identidade no Brasil: da Itália ao vinho tipicamente brasileiro. In: VIII Encontro de Grupos de Pesquisa - Engrup., VII, 2015. Florianópolis. Anais... Florianópolis, 2015, p. 60-61.

FLORES, S. S.; MEDEIROS, R. M. V. Ruralidades na compreensão dos territórios do vinho e sua identidade. CAMPO-TERRITÓRIO: revista de geografia agrária. Uberlândia. v. 8, n. 15, p. 1-19, fev., 2013. Disponível em: http://www.seer.ufu.br/index.php/campoterritorio/issue/view/971. Acesso em: 3 jun. 2014.

FONTOURA, L. F. M. A produção social do espaço agrário. In: VERDUM, R.; BASSO, L. A.; SUERTEGARAY, D. M. A. (Org.). Rio Grande do Sul: paisagens e territórios em transformação. Porto Alegre, 2004. p. 233-246.

A relação campo-cidade como método. In: MEDEIROS, R. M. V.; FALCADE, I. (org.). Tradição versus tecnologia: as novas territorialidades do espaço agrário brasileiro. Porto Alegre: Ed. da UFRGS, 2009. p. 269-283.

Campo, cidade e a natureza recriada na artificialidade urbana.

Boletim Gaúcho de Geografia. Porto Alegre, 36: 43-51, maio, 2011.

FORTUNATO, A. Vitivinicultura na Campanha Gaúcha. Santana do Livramento. 11 de fev. 2016. Entrevista concedida a Vanessa Manfio.

GUATAMBU - ESTÂNCIA DO VINHO. Fotos dos vinhos. Disponível em: http://www.guatambuvinhos.com.br/album.php?ida=6\#divMenuUtil. Acesso em: 20 de set. de 2016.

HARVEY. D. A justiça social e a cidade. São Paulo: HUCITEC, 1980.

A produção capitalista do espaço. São Paulo: Annablume, 2005.

HESPANHOL, A. N. Agricultura, desenvolvimento e sustentabilidade. In: MARAFON, G. J.; RUA, J.; RIBEIRO, M. (Org.). A. Abordagens teórico-metodológicas em geografia agrária. Rio de Janeiro: Ed. UERJ, 2007, p. 179-198. 
HESPANHOL, R. A. de M. Campo e cidade, rural e urbano no Brasil contemporâneo. Mercator, Fortaleza, v. 12, número especial (2), p. 103-112, set. 2013.

LEFEBVRE, H. O direito à cidade. São Paulo: Documentos LTDA, 1969.

A Revolução urbana. Belo Horizonte: Ed. UFMG, 1999.

MARTINS, J. de S. Os camponeses e a política no Brasil. Petrópolis: Vozes, 1986.

MEDEIROS, R. M. V. Que "novo" rural é esse no Brasil? Palestra proferida na mesa redonda "Dilemas da conceitualização do campo e do rural no Brasil" no Simpósio Urbano-Rural - USP, São Paulo. 2006.

MEDEIROS, R. M. V. Dilemas na conceituação do campo e do rural no Brasil. In. SAQUET, M. A.; SUZUKI, J. C.; MARAFON, G. J. (Org.). Territorialidades e diversidade nos campos e nas cidades latino-americanas e francesas. São Paulo: Outras Expressões, v. 1, 2011, p. 59-66.

MOTA, D. M. da; SCHMITZ, H. Pertinência da categoria rural para análise social. Ciências Agrotecnicas, v. 26, nº 2, p. 392-399, 2002.

MÜLlER, G. Complexo Agroindustrial e Modernização Agrária. São Paulo: Hucitec, 1989.

OLIVEIRA, A. L. de; MIORIN, V. M. F. A influência dos complexos agroindustriais na dinâmica sócio-espacial de pequenos municípios. Revista Geográfica de América Central, Número Especial EGAL, 2011.

PERES, G. S. A atuação da Associação dos Produtores de vinhos da Campanha Gaúcha. Bagé. 5 de outubro de 2016. Entrevista concedida a Vanessa Manfio.

PERUZZO, E. A vitivinicultura e enoturismo da Vinícola Peruzzo. Bagé. 4 de outubro de 2016. Entrevista concedida a Vanessa Manfio.

PITTE, J. R. O desejo do vinho conquistando o mundo. Tradução de Carmem Ferrer, São Paulo: Editora SENAC São Paulo, 2012.

PROTAS, J. F. da S.; CAMARGO, U. A.; MELO, L. M. R. de. A vitivinicultura brasileira: realidade e perspectivas. Embrapa Uva e Vinho, Bento Gonçalves, 2014. Disponível em: http://www.cnpuv.embrapa.br/publica/artigos/vitivinicultura/. Acesso em: 12 de dez. de 2014.

PROTAS, J. F. da S.; CAMARGO, U. A. Vitivinicultura brasileira: panorama setorial. Brasília, DF: SEBRAE, 2010. 
QUEIROZ, M. I. P. Cultura, Sociedade Rural, Sociedade Urbana no Brasil. Rio de Janeiro: Livros técnicos e Científicos, USP, 1978.

RAMBO, A. G.; FONTOURA, L. F. M. A relação cidade-campo na discussão sobre o desenvolvimento territorial local/regional nos COREDES Fronteira Noroeste e Missões/RS. Anais... In: XLV CONGRESSO DA SOBER. Londrina, 22-25 de jul. 2007.

SANTOS, M. A natureza do espaço: Técnica e tempo. Razão e Emoção. São Paulo: HUCITEC, 1996.

SILVA, W. R. da. Reflexões em torno do urbano no Brasil. In: SPOSITO, M. E. B.; WHITACKER, A. M. (Org.). Cidade e Campo: relações e contradições entre urbano e rural. São Paulo: Expressão Popular, 2006. p. 65- 80.

SILVA, P. F. J. da; HESPANHOL, R. A. de M. Relações cidade-campo e urbano-rural: contribuição para a análise geográfica do projeto cinturão verde de Ilha Solteira, São Paulo e para o programa vilas rurais em Lerroville, Paraná, Brasil. Revista Geoatos. Presidente Prudente, n. 11, v.2, jul. a dez. de 2011, p.33-48. Disponível em: http://revista.fct.unesp.br/index.php/geografiaematos/article/viewFile/250/paulo.Acesso: 11 jun. 2014.

SUZUKI, J. C. Modernização, território e relação campo- cidade: uma outra leitura da modernização agrícola. In: MEDEIROS, R. M. V.; FALCADE, I. (org.). Tradição versus tecnologia: as novas territorialidades do espaço agrário brasileiro. Porto Alegre: Ed. da UFRGS, 2009. p. 241-253. 